\title{
Targeting nickel sulfide deposits from 3D seismic reflection data at Kambalda, Australia
}

\author{
Milovan Urosevic ${ }^{1}$, Ganesh Bhat ${ }^{2}$, and Marcos Hexsel Grochau ${ }^{3}$
}

\begin{abstract}
The greenstone belts of the Yilgarn Craton, Western Australia, host numerous Archaean gold, nickel, and iron ore deposits. These deposits typically are found in complex geologic structures hidden by a deep, heterogeneous, and often conductive regolith profile. This added complexity limits the depth of penetration for the potential field methods, but at the same time opens new revenue possibilities through the application of seismic methods. To explore this opportunity, we acquired highresolution, experimental, 3D seismic data over Lake Lefroy in Kambalda, Western Australia. The main objective was to map exceptionally complex, deep structures associated with Kambalda dome. Survey design used 3D ray tracing to improve the distribution of the common reflection points across ultramafic-basalt contacts which host numerous small, high-grade nickel sulfide deposits. A combination of small explosive sources, high-shot/receiver density, and exceptionally good coupling
\end{abstract}

over the ultrasalty lake surface produced seismic data of very high quality. Processing focused on computation of accurate static and dynamic corrections, whereas imaging was helped by the existing geologic model. Advanced volumetric interpretation supported by seismic forward modeling was used to guide mapping of the main lithological interfaces and structures. Forward modeling was carried out using rock properties obtained from ultrasonic measurements and one borehole, drilled in the proximity of the 3D seismic volume. Using this information, geometric constraints based on the typical size of ore bodies found in this mine and a simple window-based seismic attribute, several new targets were proposed. Three of these targets subsequently have been drilled and new zones of mineralization were intercepted. The case study presented demonstrates that high-quality, high-resolution, 3D seismic data combined with volumetric seismic interpretation could become a primary methodology for exploration of deep, small, massive sulfide deposits distributed across the Kambalda area.

\section{INTRODUCTION}

Traditionally, nickel exploration was based on geologic and geochemical methods, such as lithogeochemical and hydrogeochemical analyses (Barnes et al., 2004). Since the 1970s, more and more geophysical exploration methods, like gravity and electromagnetics, have been adopted by the industry (Dentith et al., 1994; Mutton and Peters, 2004). However, these methods normally are not effective for depths greater than $400 \mathrm{~m}$, particularly in Australian conditions. Of particular interest to mining companies are massive sulfide (MS) deposits, which are low-volume but high-grade deposits. Unfortunately, massive sulfide ore bodies occur at considerable depths in Archean igneous and metamorphic terrains, and often are associated with excessively complex geologic structures. Consequently, these deposits are very hard to discover by traditional geologic or geophysical methods.

The recent boom in nickel mining has prompted mining companies to adopt various combinations of surface and downhole exploration methods. Known massive sulfide deposits occurring at shallow depths were more or less mined out in the Kambalda region and possibly also around the world. Consequently, miners are now seeking deep-seated concealed ore bodies. However, target depths of 600 to $1200 \mathrm{~m}$ makes exploration reliant on drilling, which is risky and uneconomical. Hence, Consolidated Minerals decided to experiment with the seismic reflection method and assess its

\footnotetext{
Manuscript received by the Editor 19 December 2011; revised manuscript received 30 April 2012; published online 6 September 2012.

${ }^{1}$ Curtin University, Department of Exploration Geophysics, and Deep Exploration Technologies Corporative Research Centre (DETCRC), Perth, Western Australia. E-mail: m.urosevic@curtin.edu.au.

${ }^{2}$ Consolidated Minerals Limited, Perth, Western Australia. E-mail: gbhat@consminerals.com.au.

${ }^{3}$ Curtin University, Department of Exploration Geophysics, Perth, Western Australia. E-mail: marcosgrochau @yahoo.com.

(C) 2012 Society of Exploration Geophysicists. All rights reserved.
} 
applicability for exploration of deep and complex MS deposits in Kambalda, in the eastern goldfields district of Western Australia. Such an attempt was encouraged by several successful experimental surveys reported by Greenhalgh and Mason (1997), Calvert and Li (1999), Milkereit et al., (1991, 1996, 2000). Moreover, successful case histories in the Kambalda region, which is thoroughly studied by explorers for nickel and gold deposits (Neumayr et al., 2004) were reported by Stolz (2003) and Urosevic et al. (2005).

The main objective of this study was to assess the true potential of 3D seismic methodology for delineation of the Kambalda dome and its complex nickel-bearing structures. The expectation of this study was to improve the knowledge of subsurface geology related to massive sulfide deposits between depths of 300 and $1200 \mathrm{~m}$. For that purpose, we designed a high-resolution, mini-3D seismic survey. Available 3D geologic models, core sample tests, and borehole information were used in the design, and also later during the processing and interpretation stages. Advanced volumetric interpretation tools were used to delineate main structures, map rock contacts of relevance for the mineralization, and, in the last stage, to indicate seismic anomalies that could relate to nickel sulfide deposits. The methodology used resulted in new discoveries.

\section{LOCAL GEOLOGY}

Nickel sulfide deposits in the Kambalda area are closely associated with Archean komatiite, a type of ultramafic rock (Lesher, 1989; Cowden and Roberts, 1990). The identification of interfaces between the Lunnon basalt, Kambalda Komatiite, Devon Consols basalt, and various intrusive rocks is very important in the nickel exploration process. Most individual ore shoots are located either on or very close to the contact between Lunnon basalt and the overlying ultramafic rock termed "Kambalda komatiite" (Stone and Archibald, 2004). Kambalda sulfide deposits belong to the a)

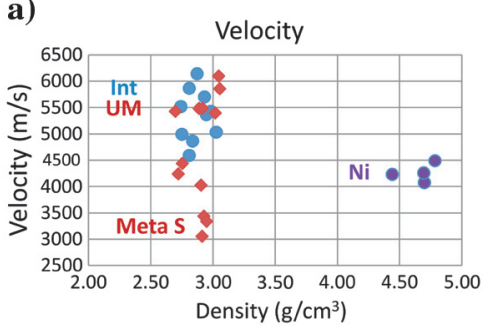

MS - massive sulfides, Int- intermediate volcanics UM - ultramafics, MetaS - meta sediments b)

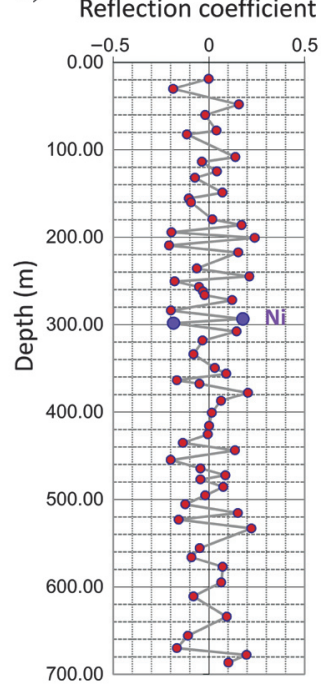

Figure 1. Core sample test results for (a) velocity versus density, using samples from two boreholes that intercepted high-grade ore. $\mathrm{Ni}$ ore stands out, which gives rise to a good contrast between ore and the host rocks. (b) Samples taken from boreholes drilled close to 3D survey area; pseudoimpedance log constructed from a large number of core samples measured in BH-336 that intercepted $0.5 \mathrm{~m}$ of low-grade sulfides. $\mathrm{BH}-336$ is located over $500 \mathrm{~m}$ away from seismic volume. volcanogenic massive sulfides category. The currently accepted hypothesis is that during the Archaean era, "lava rivers" were spilled over this area on top of preexisting basalt rocks. The Ni sulfide particles clogged up together to form MS deposits. Because their density is higher than the surrounding silicate minerals, most of the nickel sulfides were deposited at the bottom of lava channels near the basalt contact. Some of the sulfide masses were remobilized during later hydrothermal metamorphic events. As such, most of the massive sulfide mineralization deposits are of a small size. A typical ore body size will be $3 \mathrm{~m}$ thick and occupy an area of $600 \mathrm{~m}^{2}$. For a specific gravity value of $4000 \mathrm{~kg} / \mathrm{m}^{3}$ and nickel assay of $5 \%$, a body of that size will contain approximately 360 tons of nickel. At the current market value, such a find would be worth several million dollars. However, a target of such a size is hard to find by drilling, particularly at several hundreds of meters to 1.5 kilometer depths.

The Kambalda nickel sulfide deposits occur on either side of a tectonically controlled, doubly plunging anticline known as the Kambalda Dome (Stone and Masterman, 1998). Due to structural complexities in the area, exploration for massive sulfides becomes very challenging at greater depths (600 $\mathrm{m}$ and deeper). On the positive side, tests on drill core showed that the elastic properties of mineralized rocks stand out from their host rock, and are expected to provide sufficient contrast in acoustic impedance to produce readily detectable reflection events (Figure 1). Some sparse measurements of high-grade $\mathrm{Ni}$ ore (5.0 to $5.5 \%$ ) extracted from two boreholes close to the northern edge of seismic volume are presented in Figure 1a. The nickel sulfide samples clearly stand out from the host rocks in the impedance density crossplot. A significant number of core tests were completed for BH-336, which penetrated a lowgrade Ni ore $0.5 \mathrm{~m}$ thick. A pseudoreflectivity log was created for $\mathrm{BH}-336$, which shows that the low-grade $\mathrm{Ni}$ ore plots within the background trend (Figure 1b). Full-waveform-sonic and density logs only were available for one surface borehole (LD105). Unfortunately, this borehole was drilled at the southern edge of the seismic volume and dipping $60^{\circ}$ away. Consequently, it did not intersect any of the rock interfaces of interest within the seismic volume. However, the borehole intersected two very thin $(0.2$ to $0.3 \mathrm{~m})$ sulfide lenses at shallow depths. These thin lenses have high density ( 3.5 and $4 \mathrm{~g} / \mathrm{cm}^{3}$, respectively) which has contributed to an elevated reflectivity as marked by the red arrow in Figure 2. The computed synthetic seismogram for LD105 suggests that sulfides in contact with the host rock could create an elevated reflectivity. However, the sonic log is of poor quality and does not permit further generalizations. We can suggest that the Kapai Slate when in contact with basalts is likely to produce good reflection. Significant velocity variations appear to be present within the Kambalda komatiites and Paringa basalt.

\section{SEISMIC DATA ACQUISITION}

The 3D seismic survey was conducted in 2007 by Geoforce Pty Ltd. Three-dimensional design and logistics were provided by the Department of Exploration Geophysics, Curtin University. Data was acquired above Beta Hunt nickel mine on Lake Lefroy, south of the Kambalda township, as shown in Figure 3a. The 3D area was nested between abandoned gold mine pits, man-made mullock heaps, dikes, and old and new mine infrastructure (Figure 3b). The main causeway connecting St. Ives mine camp to Kambalda cut through the $3 \mathrm{D}$ seismic area. The total area covered by the 
shot/receiver lines was approximately $3.5 \mathrm{~km}^{2}$. The shot-line separation varied from a nominal separation of $100 \mathrm{~m}$ to $50 \mathrm{~m}$, and less (down to $10 \mathrm{~m}$ ) where patches overlapped. Receiver line separation was kept to around $90 \mathrm{~m}$. Four patches, each consisting of six receiver lines with a variable number of channels (up to 500), were used to cover the 3D area (Figure 3c). Nominal receiver separation was $10 \mathrm{~m}$ and shot separation was $20 \mathrm{~m}$. Small explosive charges $(110 \mathrm{~g})$ were deployed in 1.2 to $1.5 \mathrm{~m}$ deep holes. On the hard ground, away from the salt lake, a free fall weight drop $(375 \mathrm{~kg})$ was used to generate seismic energy. The nominal fold for $5 \times 10 \mathrm{~m}$ bins was design to be around 70 . The fold analysis and the processing used a $10 \times 10 \mathrm{~m}$ bin size to double the fold. To analyze the common reflection point (CRP) distribution over the Kambalda Dome, we used 3D ray tracing. Comparing the CRP to a conventional common midpoint (CMP) fold helped the final survey design. It was necessary to introduce additional source lines running approximately in a south-southwest - north-northeast direction to improve the CRP fold (Figure 4). A higher bin size was used for the CRP display due to the fact that some rays were lost in the computation process. Therefore, the surface and the underground fold maps only can be compared in a qualitative sense. It is clear that the displacement between the CMP and CRP points can be significant, and that the CRP fold is more appropriate for illumination of dipping structures such as the Kambalda Dome.

The final 3D design, however, was not followed exactly due to a large storm and subsequent surface flooding of the salt lake midway through the acquisition of patch 3 . It took over three months for the lake to dry and for DEG to repair the equipment damaged by the hypersaline water. Upon recommencement of the survey, modifications had to be made to the source and receiver lines to accommodate ground conditions. The final distribution of the source and receiver lines and the related CMP fold are shown in Figure 5. The average shot density achieved across the 3D survey was 630 shots $/ \mathrm{km}^{2}$. The receiver density was around 550 receivers/ $\mathrm{km}^{2}$, some 80 receivers $/ \mathrm{km}^{2}$ less than designed. These changes produced lower fold in some parts of the survey. The final area covered by the 3D fold is approximately $2.2 \times 1.2 \mathrm{~km}$. Inlines are oriented in southeast-northwest direction, crosslines are running southwest-northeast.

Data processing and interpretation was carried out at Curtin University. Acquisition and processing stages took about 12 months to be completed, and in August 2008 the seismic volume was available for the interpretation stage.

\section{DATA PROCESSING}

Noise generated by the underground drilling activities and heavy vehicles of Beta Hunt nickel mine were, to a large extent, avoided by careful recording that included frequent breaks in acquisition until the noise level was acceptable. Consequently, excessive ambient noise bursts contaminated less than $5 \%$ of the shots recorded. The data acquired after flooding included reacquiring half of patch three (west of causeway, Figure 3c). The repeated geophone stations

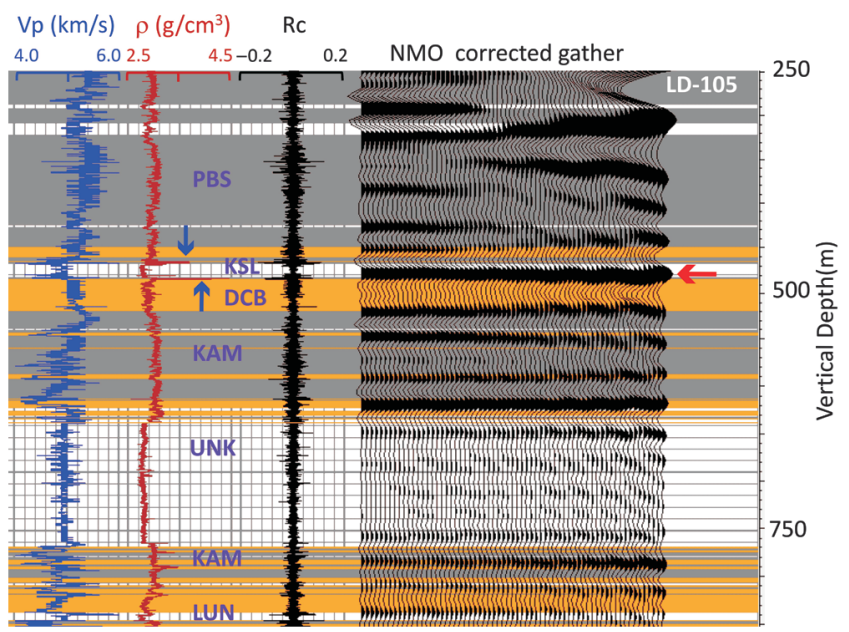

Figure 2. Full elastic synthetic seismogram computed for borehole LD-105 using offset range 0-900 m. The rock codes are: PBS Paringa basalt, KSL - Kapai Slate, DCB - Devon Console basalt, KAM - Kambalda komatite, UNK - Unknown rock type, LUN - Lunnon basalt. Stratigraphic tops and bottoms are marked with orange and gray zones, respectively. White zones stand for unknown rock units. White arrows show thin high-density sections. Red arrow shows elevated reflectivity, resulting probably from a combined effect of thin bed interference and the presence of high density lenses. Sonic $\log$ is of a low quality and should be taken with caution.

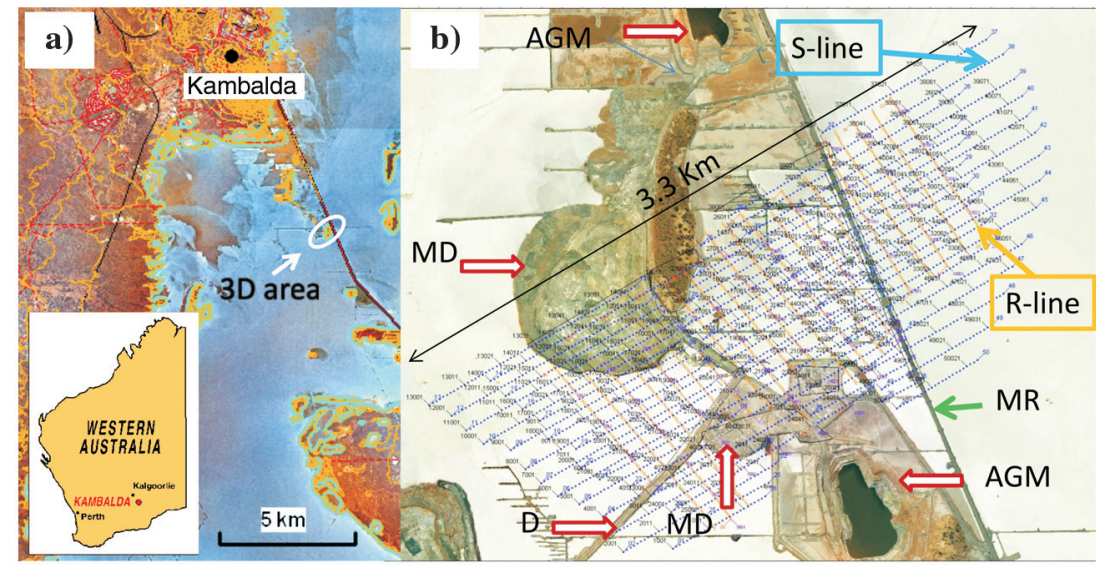

c)
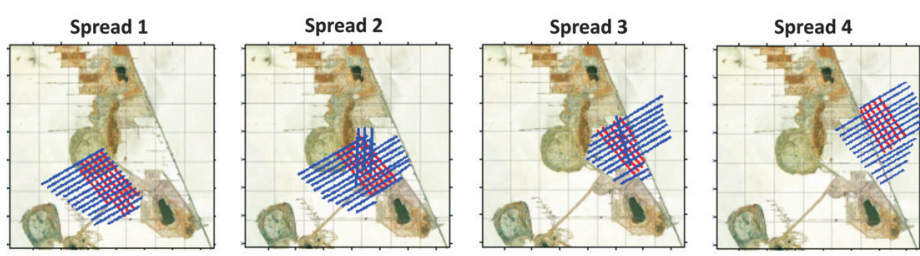

Figure 3. Three-dimensional seismic experimental survey was carried out close to Kambalda, some $600 \mathrm{~km}$ west of Perth. Aerial photo shown in (a). Salt lake is shown in blue (flooded at the time). Broun is the elevated regolith surface. Most of the 3D area was located on the salt lake (Lake Lefroy) and as shown in (b) it is surrounded by: Abandoned gold mines (AGM), Mine dumps (MD), dikes (D), main causeway, or mine road (MR). Receiver and source lines are labelled as R-line and S-line, respectively. Four overlapping patches were used for this survey, as shown in (c). 
did not exactly match previous positions due to additional mining activities and ground disturbance, resulting in a misalignment between old and new stations. Noise bursts and misaligned geophone stations for the repeated patch made the application of surface consistent amplitudes less effective. Consequently, true relativeamplitudes — strictly speaking — were not preserved because, after initial amplitude compensation, we applied a long window (1000 ms) AGC operator. However, coupling of the source and receivers was exceptionally good because over $90 \%$ of the 3D area was acquired over hypersaline clay, close to suspension in places. Consequently, shot records that were partially scaled (spherical divergence correction and gain) were not too dissimilar from shots with the AGC applied (Figure 6). The processing flow is depicted in Table 1.

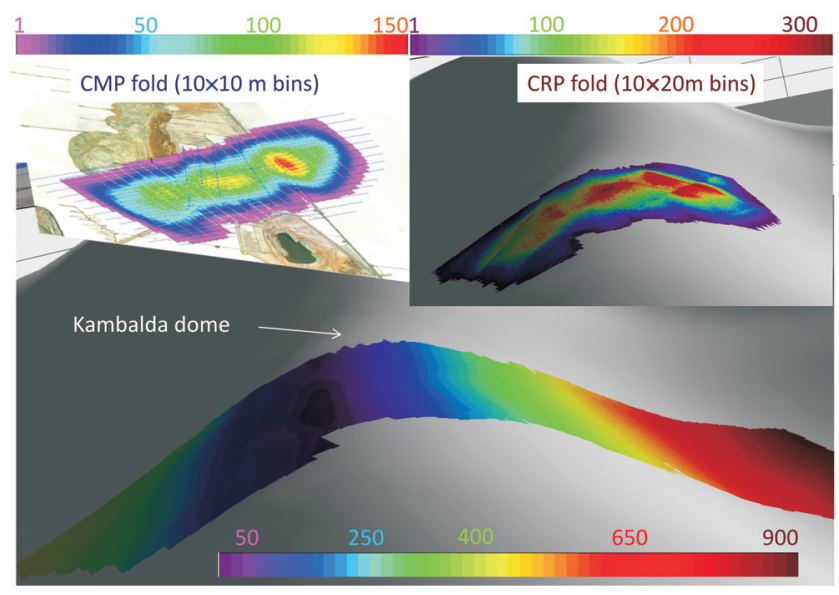

Figure 4. The surface fold map using the distribution of CMP points (top left), underground fold map using the distribution of CRP points (top right), and CRP to CMP difference map (bottom). Displacements between the two along the structure are proportional to the dip angle.

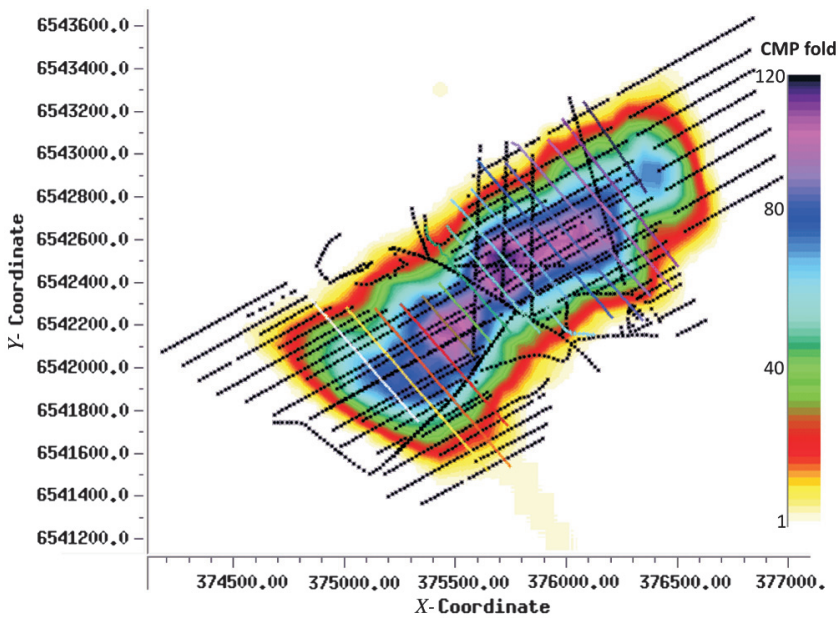

Figure 5. The final CMP fold map for bin size $10 \times 10 \mathrm{~m}$. Source lines shown in black are mainly running in southwest-northeast direction. Receiver lines (multicolored) are oriented southeastnorthwest. Note that only the central part of the $3 \mathrm{D}$ area has a fold over 80 .
One of the key objectives in hard rock seismic data processing in Australia is to "homogenize" the regolith; that is, to solve for time delays caused by heterogeneous near-surface low-velocity zones (Urosevic et al., 2007). In the case of the Beta Hunt 3D survey, which was shot mainly across the salt lake, the regolith heterogeneities were only moderate in comparison to other areas in the Kambalda region. A 3D raw shot record before and after application of refraction statics is shown in Figure 7. The total magnitude of statics (shot + receiver) topped $54 \mathrm{~ms}$ over the salt lake and was up to $70 \mathrm{~ms}$ away from the lake due to elevated shot statics (Figure 8). Shot statics were significantly greater over the hard ground in comparison to shots fired on the salt lake. Accurate computations of the delay times through the regolith were necessary to retain frequency content of the stacked section and achieve reflection continuity. A geologically meaningful velocity field was estimated through constant velocity stacks (CVS) computed along the full line length in the inline and crossline directions at an interval of $200 \mathrm{~m}$. An example of CVS panels for the central crossline is shown in Figure 9. It is relatively easy to form a mental picture of the underground structures and derive discrete velocity functions from CVS panels.

Subsequent velocity runs included interactive semblance analysis centered around CVS-derived velocity functions. The maximum departure of the semblance-derived velocities from CVS guide functions was limited to $\pm 200 \mathrm{~m} / \mathrm{s}$. Therefore, the main purpose of semblance analysis was to fine-tune CVS derived velocities.

A selection of four inlines, extracted from the cube after application of residual statics and AGC before stack, is shown in Figure 10. Very strong reflectivity originating from Beta West complex is seen

a)

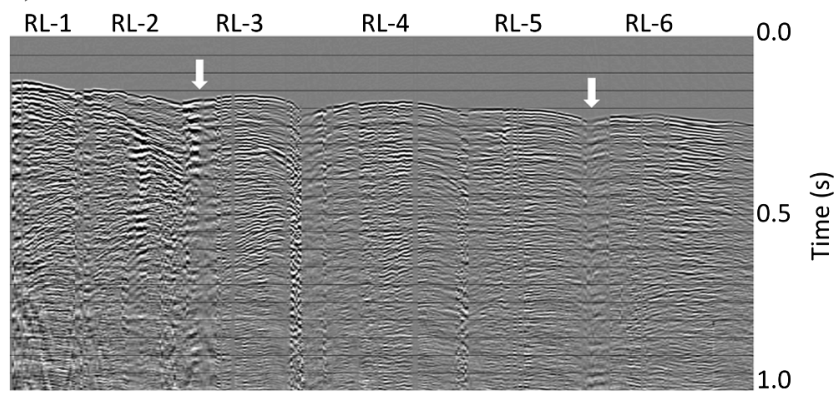

b)

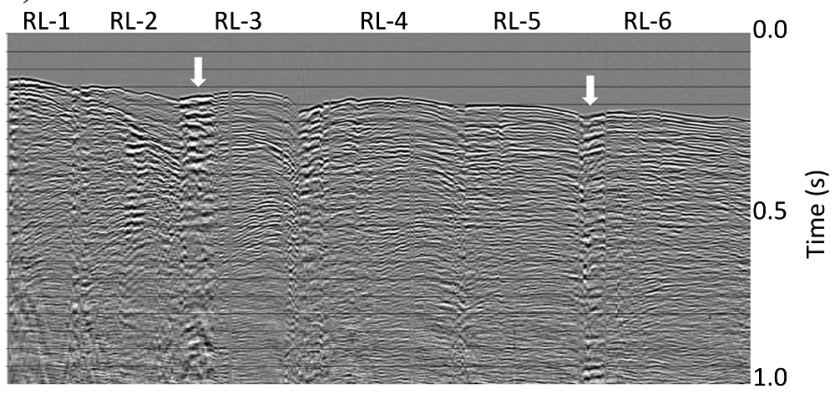

Figure 6. Three-dimensional shot record after: (a) application of spherical divergence and gain corrections and (b) after AGC $1000 \mathrm{~ms}$ operator was applied in addition. Receiver lines are labelled as RL-1 to RL-6. The two records are similar apart from some noisy sections like the one at the start of RL-3 and RL-6, which are overcalled by the application of AGC. This effect is diminished by the subsequent application of deconvolution and filtering. 
at around $250 \mathrm{~ms}$. The difference in overall reflectivity between the western and eastern part of the section is apparent. The amplitude ratio of strong to weak reflectors is of the order of $20: 1$. It also appears that the reflection continuity could benefit from further scaling. This was not performed, but the inspection of 3D stacks at various stages of the processing suggested that the adopted processing flow has not significantly affected relative amplitudes. Selected in and crosslines, after application of DMO and 3D depth migration, are shown in Figure 11. High data quality enables early identification of a known Beta shoot Ni deposit and a less explored deep Alpha shoot deposit. High data quality is attributed to (1) next to perfect coupling of source and receiver over the salt lake, (2) 3D

\section{Table 1. Basic 3D processing flow.}

Geometry specification/binning

Trace edit/reverse/mute

Shot energy equalization, spherical divergence correction, and $6 \mathrm{DB} / \mathrm{s}$ gain

First-arrival picking, editing, and refraction static calculations

Signal and noise analysis

Application of spiking deconvolution (80 ms operator, $1000 \mathrm{~ms}$ window), followed by broad band-pass filtering

Constant velocity stacks: Selected inlines and crosslines $(200 \mathrm{~m}$ increments)

Application of NMO

Stack 1, pick 3D horizon for residual statics

Residual reflection static computation

Stack 2, with surface consistent residual reflection statics applied Dip moveout correction (3D DMO, shot domain), inverse NMO

Final velocity analysis

DMO stack (scaled, AGC $1000 \mathrm{~ms}$ )

F-XY deconvolution

DMO FXY stack

Poststack time migration

Depth conversion

Depth migration

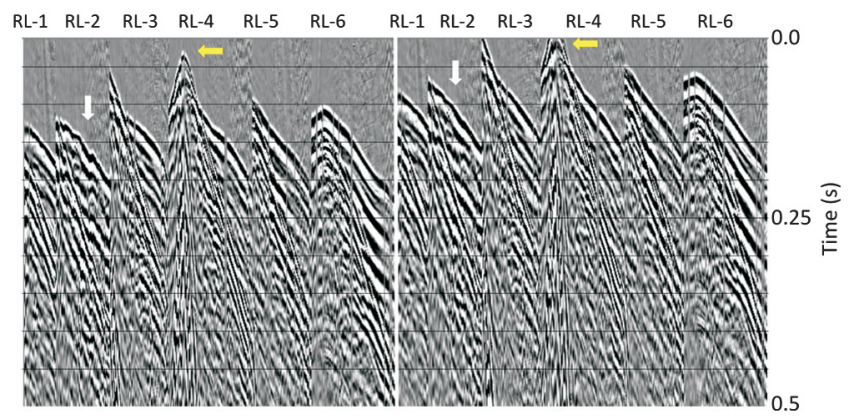

Figure 7. A 3D shot record before (left) and after (right) application of refraction statics. Equalized amplitudes shown. Note that statics have significant magnitude across receiver line 2 (white arrow). The shot static also is large, as marked by the horizontal yellow arrow. design that used high data density, and (3) high-precision data processing, particularly static and dynamic corrections.

\section{DATA INTERPRETATION}

Application of seismic technology for the mineral industry is not a common practice, hence typical mining software designed for resource calculations, such as Micromine, Vulcan, and Surpac, are not suitable for interrogating 3D seismic data cube. To overcome this, we loaded our data into an oil-type interpretation package capable of volumetric interpretation. The issue then becomes how to integrate 3D geologic models, other geophysical measurements, and mining information with a seismic cube. The use of local mine coordinates in production further complicates seismic data analysis. Apart from geologic models, which are important for guiding the initial interpretation, it is necessary to calibrate seismic to assign geologic meaning to the measured reflectivity, achieve proper calibration, and speed up the interpretation process. Because only one sonic log, of low quality and away from the seismic cube, was available, we loaded drillhole trajectories and intercepts (or tops) corresponding to relevant geologic interfaces to help calibrate seismic data.

\section{VOLUMETRIC VERSUS CONVENTIONAL INTERPRETATION}

There are two different methodologies available to seismic interpreters. One approach is to interpret 3D volumes based on 2D slices, interpreting line-by-line. This is called "conventional" interpretation and has been used for decades in the oil industry. Another approach, called "volumetric," is to interpret 3D volumes in a real 3D way. This is performed by applying opacity and transparency filters, displaying and rotating objects, using special visualization techniques (like stereoscopy), and so on. The latter approach allows a much more comprehensive understanding of the volume under investigation. In the present study, we interpret the Kambalda seismic volume using the volumetric interpretation approach.

Initially, structural patterns from seismic data were analyzed, and then the semblance attribute was computed, aiming to enhance discontinuities. Despite testing various parameters, semblance did not work well due to the presence of no data zones and associated low $\mathrm{S} / \mathrm{N}$ in some parts of the cube. Consequently, a simple "Perigram" (low-pass filtered envelope, multiplied by the cosine of the instantaneous phase) and amplitude were the most useful attributes to map faults at all scales (Figure 12). Investigating the seismic volume in vertical planes at different directions, and in horizontal and dipping slices, made it possible to reveal full diversity and complexity of underground structures. Normal, reverse, dextral, and other fault patterns were identified based on breaks in continuity of several discrete reflections, or changes in dips of successive reflectors, or based on a termination of a reflective package (Figure 12). The major (known) faults, such as the Alpha Island fault, were interpreted first. Despite the decrease in seismic quality toward the edges of the seismic volume where the fault is located, it was still possible to identify and interpret this fault by examining depth slices and considering its predominantly dextral movement component. Figure 13a shows the previously interpreted Alpha Island fault inferred from drilling and the new interpretation based on seismic data. Both interpretations show similar direction (north-northeast - south-southwest) in the area covered by the seismic volume, but they differ in dip angle and fault complexity. We interpreted 


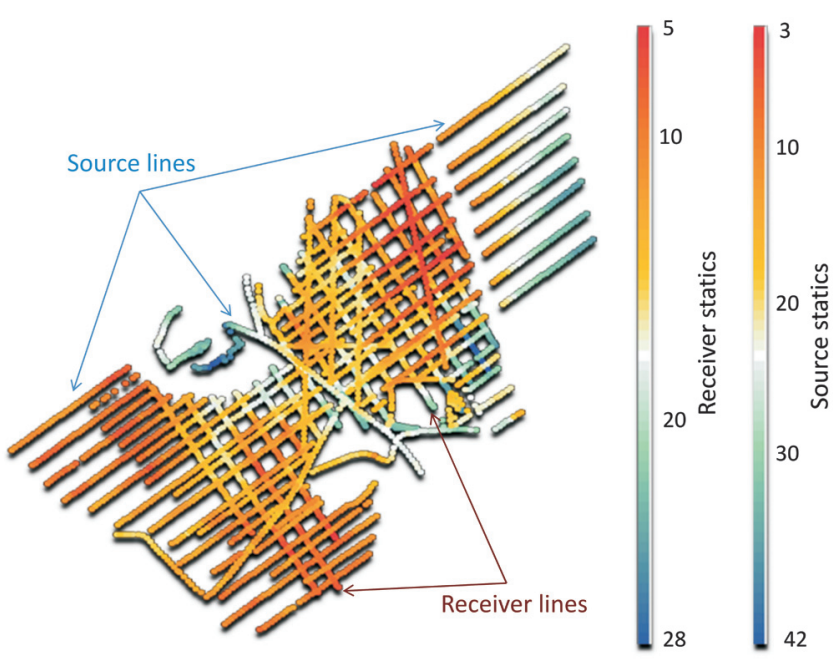

Figure 8. Color-coded shot and receiver statics displayed along the lines. Shot lines are running southwest-northeast, receiver lines southeast-northwest. A total maximum static of $70 \mathrm{~ms}$ is encountered only when shots were positioned on the hard ground (dikes, mullocks), away from the salt lake. Over the salt lake, the total static is not exceeding $54 \mathrm{~ms}$, which is of low-to-moderate magnitude for this region.

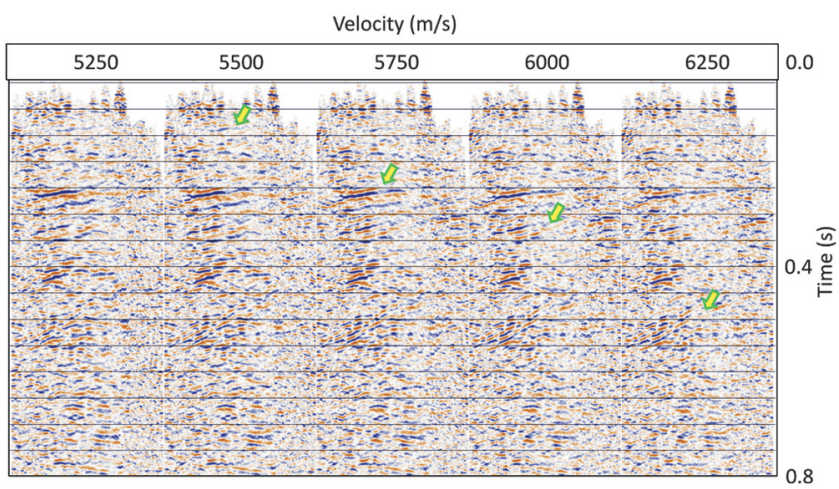

Figure 9. Constant velocity stacks for the central crossline 65. Derivation of a geologically meaningful velocity model is relatively straightforward from these panels. Identification of artifacts also is much easier than when using semblance analysis. CVS analysis was repeated after the application of residual static corrections and DMO.

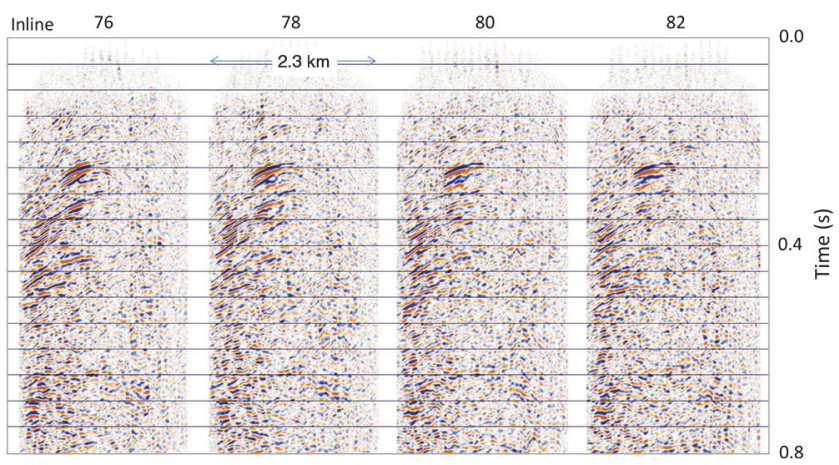

Figure 10. Selected inlines after preprocessing and application residual reflection statics. High-reflectivity patches are present in each section. The amplitude variation is significant, as is the difference between strong and weak events. this fault as a system of two subverticals, gently diverging faults toward the surface that are slightly offset with respect to the previous interpretation (Figure 13b). A significant number of small-scale faults can be interpreted from the seismic cube. Some of these faults are visible only in a few time or depth slices and then disappear. Some fault types, like reverse faults, are better seen in vertical cross sections as shown in Figure 14.

Following structural interpretation, the most relevant geologic interfaces were interpreted in $3 \mathrm{D}$. They were recognized and

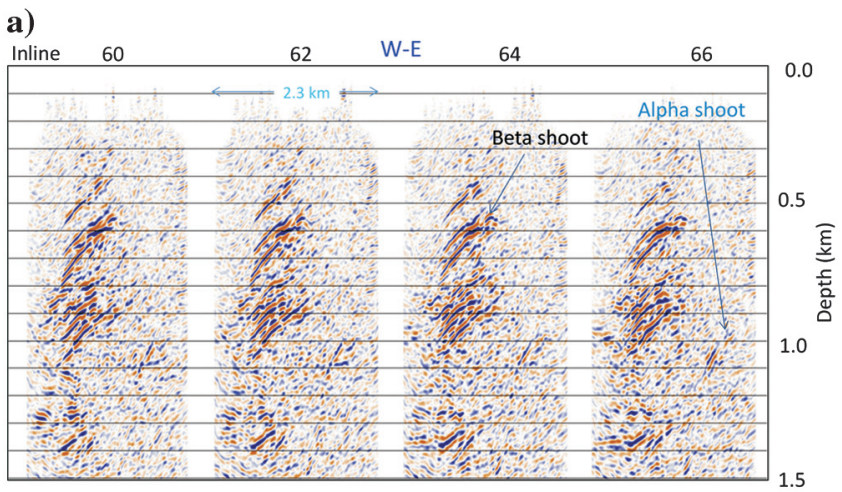

b)

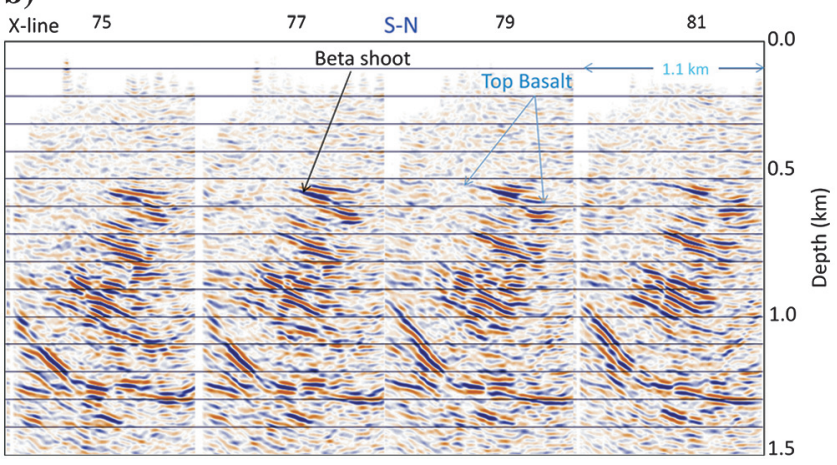

Figure 11. Extracted lines from seismic cube: (a) Inlines (top) and (b) crosslines. Line interval is $20 \mathrm{~m}$. High data quality enables early identification of a known Beta shoot $\mathrm{Ni}$ deposit and less explored Alpha shoot. Crossline sections appear smoother due to different horizontal scale. Average inline is approximately $2.4 \mathrm{~km}$ in length, about twice as long as the average crossline.

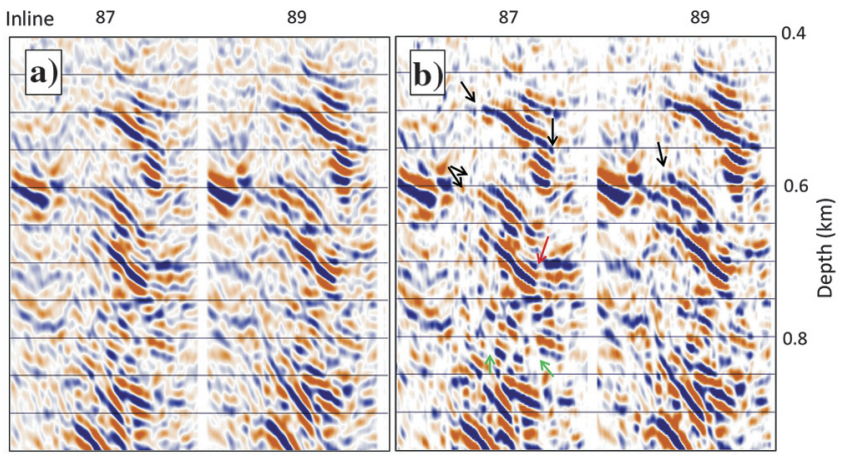

Figure 12. Inlines 87 and 89 depth sections: (a) Amplitude section and (b) Perigram section (low pass envelope scaled by instantaneous phase, corrected for 90 phase shift. Subtle faults easily are identified in Perigram section as indicated by the arrows. 
interpreted on seismic data using existing geologic models, lithological markers from drillholes, core sample tests, and forwardmodeling experiments. The main geologic units interpreted are the Devons Consol basalt, Kambalda Komatiite, intrusive rocks into the Kambalda Komatiite, and intrusive rocks into basalts. Opacity filters were particularly effective in highlighting sill and dike intrusions into ultramafic rocks. The seismic signature of those interfaces has predominantly high amplitudes with good lateral continuity. Some of the intrusives mapped in the seismic volume are shown in Figure 15.

\section{TARGETING MASSIVE SULFIDE DEPOSITS}

The Beta Hunt active underground mine headings are located between 700 to $1000 \mathrm{~m}$ vertically below the surface. Mine workers, haulage trucks, and other heavy mine machinery approach the mine headings and ore bodies by driving down about $9 \mathrm{~km}$ distance through a winding network of declines. Productive MS ore bodies have a thickness ranging from $0.5 \mathrm{~m}$ to $5 \mathrm{~m}$, and very rarely to $10 \mathrm{~m}$. Strike and dip extension of these ranges between 5 to $50 \mathrm{~m}$. Most of the ore bodies were discovered by drilling an array of diamond drillholes into favorable geologic targets from suitable underground drill chambers as shown in Figure 16. Some targets are generated by downhole transient electromagnetic surveys. At these working depths, discovering or missing any massive sulfide ore bodies becomes commercially significant. Therefore, additional information provided by seismic data can help increase the drilling success rate. Similarly, precise information about the orientation of geologic structures and lithology is critically important to the development of underground mine headings.

The main objective of increasing geologic knowledge of this area using seismic data was successfully achieved in the first phase of seismic interpretation. Encouraged by the quality of seismic images, we decided to direct further efforts toward characterization of seismic amplitude anomalies. The idea was to investigate if we can infer a seismic pattern or find appropriate seismic attributes that could contain an imprint of a typical nickel sulfide mineralization at this site. Thus, our ultimate goal became to attempt to target the location of nickel sulfide deposits directly from the seismic data. One of the foreseen difficulties is related to fast rock velocities that results in a long seismic wavelength, as is typical for hard rock environments. It was clear that thin nickel bodies will not be resolved by a wavelet of $80 \mathrm{~m}$ or longer. However, the detection of nickel ore bodies will be helped by their high reflectivity. The final seismic response will depend on the ore thickness, and also the geometry of the structures. To investigate this, we performed simplified forward-modeling experiments using typical thickness and geometries of nickel ore bodies. Figure 17 shows the seismic response of a nickel-wedge, located at the ultramaficbasalt contact. The thickness of the body reduces from 10 to $0 \mathrm{~m}$. As expected, the resultant reflectivity is roughly proportional to the thickness of the ore body and a strong amplitude anomaly is not expected for nickel mineralization that is less than $43 \mathrm{~m}$ in thickness.

The seismic response of a $10 \mathrm{~m}$ thick nickel sulfide body not in constant contact with and dipping away from the ultramafic-Lunnon basalt contact is more complex due to the interference of multiple a)

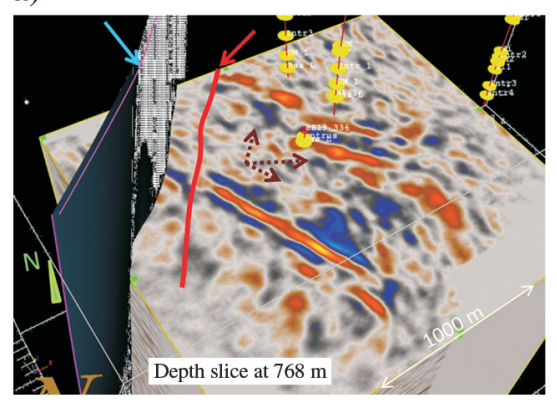

b)

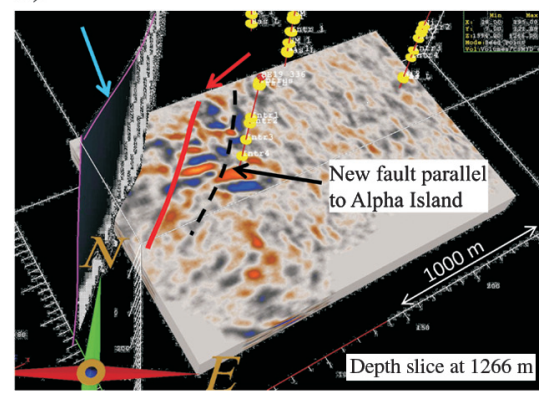

Figure 13. Alpha Island fault plane inferred from drilling is marked with blue arrow (dark plane, partially shaded in white, outlined by a thin pink line). The evidences of the actual fault plane (thick red line) position can be seen in two different depth slices: (a) $768 \mathrm{~m}$ and (b) $1266 \mathrm{~m}$. We reinterpret Alpha fault as consisting of the two planes with similar directions, but diverging toward the surface. In fact, it is possible to see that strong amplitudes are displaced in accordance with the dextral movement, as shown by the black dashed line in (b). Other faults also can be seen as indicated with brown arrows in (a). Yellow discs denote position of various intrusives, as intercepted by underground drillholes.

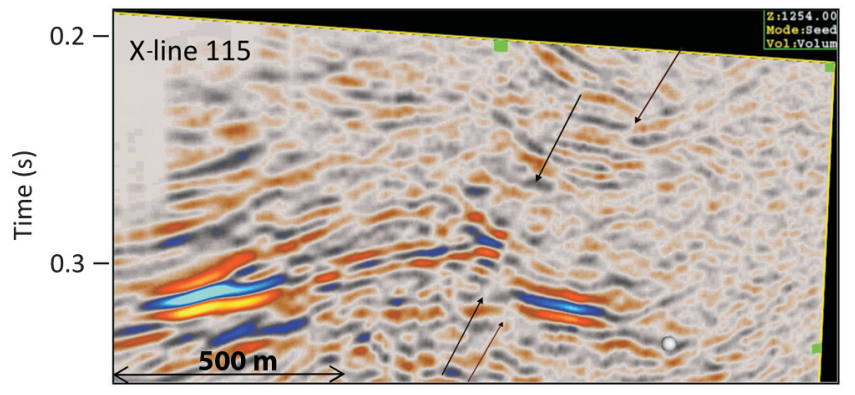

Figure 14. Reverse faults (arrows) with vertical displacement visible only in a vertical cross section. Crossline 115 displayed enlarged. Many faults of different types pervade 3D seismic cube.
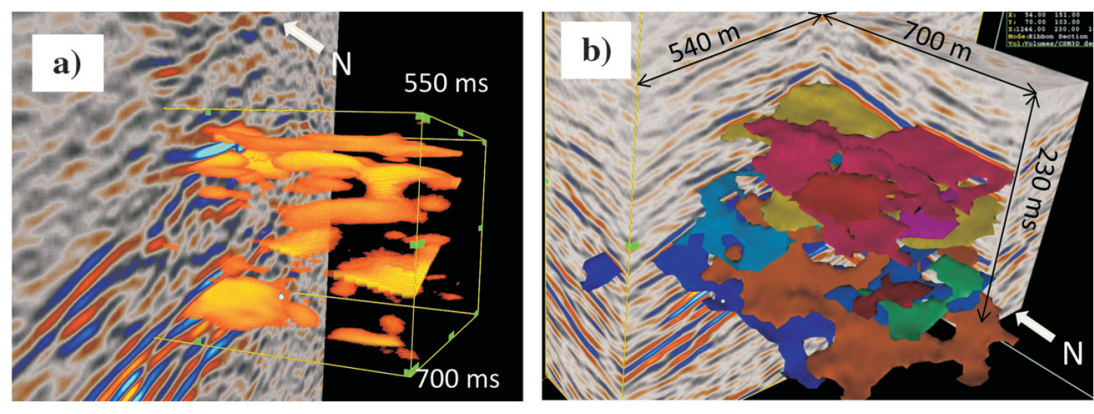

Figure 15. Sills and dikes intruded into ultramafic rocks (Kambalda komatite) are (a) extracted with the application of opacity filters and (b) subsequently mapped. The seismic signature of those interfaces has predominantly high amplitudes with good lateral continuity, extending for several hundreds of meters, typically 500-800 m. 
reflecting interfaces (Figure 18). The interference pattern changes from constructive to destructive, and for a specific geometrical condition, a 10-m thick nickel body may not be detected by seismic. In all other cases, constructive interference occurs and the reflections from nickel deposits are amplified to a variable degree. If the nickel body is at a favorable separation/distance from the ultramafic/basalt interface, then constructive interference is at its maximum and a strong seismic anomaly is produced. For noisy data, mapping these variations may be challenging.

Having a better understanding of the seismic signature of various nickel ore body geometries, we investigated the seismic response close to stratigraphic markers (intercepts) of existing drillholes (Figure 16). No boreholes were drilled from the surface within the 3D volume. A good correlation was observed between the main stratigraphic markers and our interpreted contacts such as the ultramafic/Lunnon basalt interface. Further interpretation was then guided by expected reflectivity in the vicinity of this interface

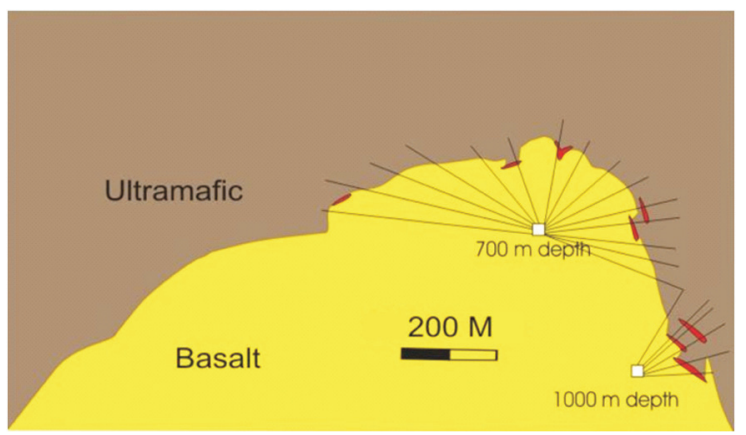

Figure 16. Arrays of diamond drillholes made from suitable underground drill chambers to locate small size massive sulfide ore bodies in Beta Hunt nickel mine.
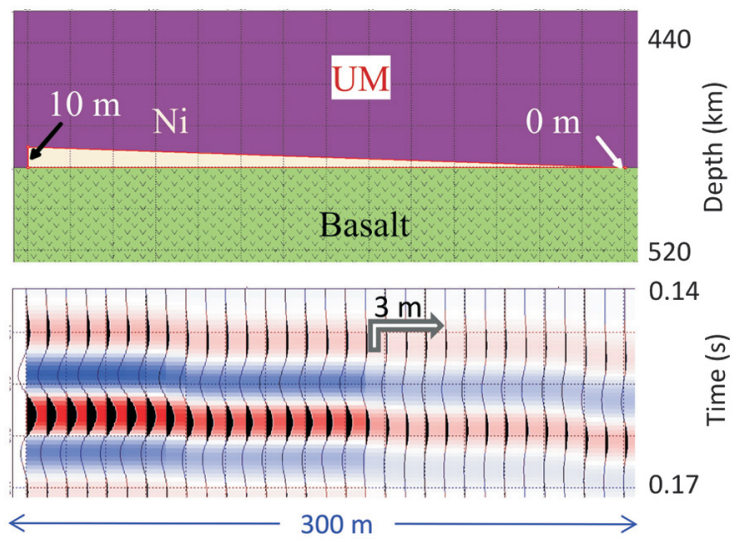

Figure 17. A simplified geologic model containing a nickel-wedge body situated at the ultramafic-basalt interface (top) and corresponding zero-offset seismic response computed with stressvelocity, finite-difference code, and $75 \mathrm{~Hz}$ Ricker wavelet (bottom image). The elastic parameters used were: UM $\left(V_{\mathrm{P}}=5600\right.$, $\left.\rho=2.9 \mathrm{~g} / \mathrm{cm}^{3}\right)$; Lunnon basalt $\left(V_{\mathrm{P}}=5500, \rho=2.85 \mathrm{~g} / \mathrm{cm}^{3}\right)$; Ni $\left(V_{\mathrm{P}}=4500, \rho=4.5 \mathrm{~g} / \mathrm{cm}^{3}\right)$. The nickel wedge is beyond the resolution limit, hence the reflectivity is roughly proportional to the thickness of the body. It is expected that very thin nickel bodies (below $3 \mathrm{~m}$ thickness) will not produce strong amplitudes. because this interface is the most likely place for nickel sulfide deposits to occur. Very high reflectivity originating from intrusives into ultramafics (often porphyries) was excluded from the targeting process. Discrimination of intrusives was largely based on significant divergence from the interpreted Lunnon interface and areal extent of typical nickel bodies encountered at this mine.

A set of seismic attributes was computed in an attempt to further enhance nickel deposits. None of the standard instantaneous attributes helped the detection process. Instead, we used the average maximum amplitude over a $100 \mathrm{~m}$ window, $60 \mathrm{~m}$ above, and $40 \mathrm{~m}$ below the Lunnon basalt and by limiting their size to 20-100 voxels, some 78 potential nickel targets were identified (Figure 19). An improved target selection was subsequently achieved by computing the root mean square (rms) amplitude for a narrow window encompassing only $10 \mathrm{~m}$ above and $4 \mathrm{~m}$ below the Lunnon basalt, and limiting the spatial extent of the potential mineralizations to $30 \times 30 \mathrm{~m}$. Figure 20 shows the rms amplitude around the ultramafic-Lunnon basalt interface. There are two known deposits as marked by the black arrows. Four other potential targets were identified in this section of the seismic volume. Three targets (white circles) shown in Figure 20 were drilled from underground drill chambers. Individual drillhole details, ore intercepts, and assay results are shown in Table 2. Note that these diamond core drillholes have positive dip, which means that the targets were intercepted from underneath, because a drill chamber is located at deeper level than are the ore bodies.

\section{DISCUSSION}

Massive sulfide deposits occurring at shallow depths in the Kambalda area have now been mined, and the main objective of exploration programs is to discover deeper targets to extend the life of existing mines. Consequently, the main objective of this experimental seismic program was to investigate the potential of 3D seismic reflection methods for mapping complex deep structures that could host massive sulfides. Apart from the issues typical for the applica-

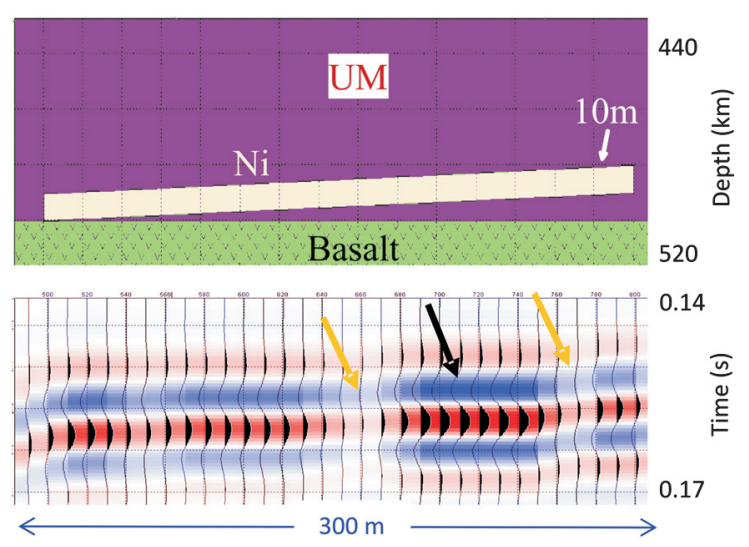

Figure 18. Seismic response of a constant thickness, dipping nickel sulfide body located close to the ultramafic-basalt interface. The same modelling parameters were used as in Figure 17. The interference pattern changes from constructive (black arrow) to destructive (orange) as a function of the separation distance between the nickel body and the ultramafic-basalt interface. Overall, a moderate amplitude response is expected unless nickel body is at the favorite separation distance (5-10 $\mathrm{m}$ from the interface). 
tion of hard rock seismic in brown fields, specific to Beta Hunt was the challenge of detecting deep seated concealed ore bodies.

The Beta Hunt Nickel Mine hosts numerous small sized massive sulfide ore bodies. In quantities, they represent good value for the

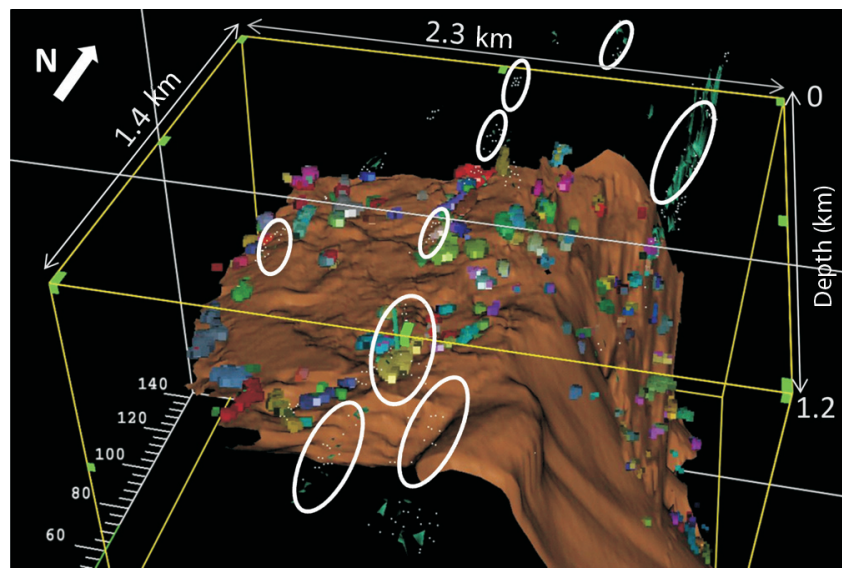

Figure 19. Potential "geobodies" or "geoanomalies" (bright colors) mapped in 3D volume, in the vicinity of ultramafic/Lunnon basalt interface (brown surface). The selection of potential targets is based on two criteria only: (1) the average maximum amplitude in a window computed around the interface of interest, and (2) the expected size of a mineralization. Known Ni occurrences (borehole intersections) are represented by tiny white dots within white ellipses.

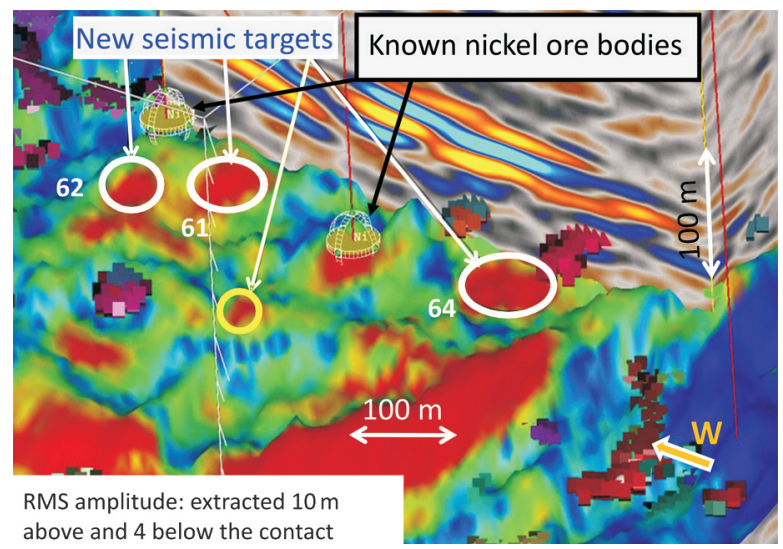

Figure 20. The rms amplitude map computed in a window around ultramafic/basalt interface. Known Ni occurrences are marked by black arrows. Proposed new targets are labelled by circles. White circles are seismic anomalies verified by underground drilling as mineralized bodies (see also Table 2). Yellow circle has not been verified by drilling at present. mine. A $3 \mathrm{~m}$ thick by $30 \mathrm{~m}$ strike by $20 \mathrm{~m}$ dip is considered a modest ore body at Beta Hunt. The value of such a discovery is well above five million dollars, and most of the proven mineralization is more or less of this value. Of course, there will be large costs involved in ore recovery from these depths; however, cost can be reduced by using already established infrastructure should nearby ore bodies be located. The probability of hitting such small bodies by underground fan drilling is small. Hence, the role of high-resolution seismic for targeting ore bodies underneath Lake Lefroy may be crucial for further development of Beta Hunt and expansion of nickel mining in the Kambalda region.

Further improvements of the methodology presented here could be made by attempting true relative amplitude processing. If any time in the future, high-quality full-waveform sonic and density logs become available within the 3D seismic volume, it would be possible to achieve proper correlation and inversion of the seismic data. The impedance cube should bring additional value and further increase the precision in targeting nickel sulfide deposits. Three-dimensional surveys of the size of $9 \mathrm{~km}^{2}$ or larger would enable further refinements of the interpretation process.

\section{CONCLUSION}

The Beta Hunt experimental survey was the first 3D survey ever acquired over Lake Lefroy. A combination of several factors, such as high data density, very good source/receiver coupling, deployment of small explosive charges, and high precision data processing produced a high-resolution, high-quality seismic data cube. The 3D volumetric seismic interpretation project was successful in achieving the primary objectives of mapping the main rock units down to $2-\mathrm{km}$ depth. The Alpha Island fault system, one of the most important structural elements in the area, is now precisely mapped and its complexity better understood. Many small-scale faults and offsets were identified within the Kambalda structural domain. The knowledge gained from these structural models will be useful for future mine infrastructure design and development.

High-precision correlation of seismic data was not possible because no surface boreholes have been drilled into the 3D seismic cube. All of the information available for the interpretation was obtained from core sample tests, underground drilling (unlogged), and borehole logs outside the seismic volume. Despite the lack of explicit correlation, numerous potential massive sulfide targets were identified within the seismic volume during the interpretation process. The use of numerical modeling proved to be important for predicting the seismic response produced by small nickel bodies and subsequently devising a targeting strategy. Simple seismic attributes in combination with the "Ni size criterion" (i.e., the restriction imposed on the lateral extent of seismic amplitude

Table 2. Drilling results and assays for three boreholes projected to verify seismic anomalies.

\begin{tabular}{|c|c|c|c|c|c|c|c|c|c|}
\hline Hole_id & Hole type & Date drilled & Azim & Dip & Depth & From & To & Intercpt_m & Grade_NiS\% \\
\hline BE23-061 & core & 24-Oct-08 & 327 & 38 & 55.4 & 20.6 & 23.7 & 3.1 & 7.97 \\
\hline BE23-061 & core & 24-Oct-08 & 327 & 38 & 55.4 & 23.7 & 27.2 & 3.5 & 2.64 \\
\hline BE23-062 & core & $25-O c t-08$ & 334 & 31 & 85 & 61.2 & 64.8 & 3.6 & 5.38 \\
\hline BE23-064 & core & 26-Oct-08 & 51 & 60 & 48 & 20 & 23.7 & 3.7 & 6.81 \\
\hline
\end{tabular}


anomalies) proved to be useful in delineating new potential targets. A total of 78 seismic exploration targets initially were interpreted and ranked according to the level of confidence. Among these targets, three of the highly ranked were drill tested. All holes intercepted massive nickel sulfide mineralization. These discoveries revealed the extension of the known ore bodies, increasing the ore resources. Interpreted exploration targets could play a very important role in improving an otherwise very low drilling success rate in the Kambalda area. The case study presented demonstrates that high-quality, high-resolution, 3D seismic data combined with a volumetric seismic interpretation could play a very important, if not crucial, role in future discoveries of deep, small, MS deposits distributed across the Kambalda Dome.

Started as an experimental survey, this seismic cube can now be "revisited" any time in future mine operations to assist with ore body targeting and mine development, particularly after new knowledge is acquired through further underground drilling assays, core sample tests, and improved geologic models.

\section{ACKNOWLEDGMENTS}

We would like to thank staff of Consolidated Minerals: Rob Henderson, Exploration Manager, Tim Craske, former Chief Exploration Geologist, Gary Snow, Former Geology Manager and Brett Davies, General Manager for providing us with the opportunity to work in this project. We also thank Abraham Whaanga, Angela Storkey, Brett Davies, General Manager Geology, Sarah Jones, and Gemma King for the technical discussions, as well as Elizabeth Florkiewicz for providing dxf surfaces. We would like to thank the Center for High-Definition Geophysics (CHDG) at the Department of Exploration Geophysics, Curtin University, for conceiving and carrying out this project. We are grateful to Anton Kepic, director of the CHDG, and now Program Leader for the Deep Exploration Technologies Corporative Research Center (DETCRC), and Peter Williams, currently of HiSeis Pty Ltd, who initiated seismic surveying and designed data acquisition strategy in hipper-saline conditions of Lake Lefroy in 2005. We thank Geoforce Pty. Ltd. for carrying out very challenging data acquisition program at the lake. We thank Sinem Yavuz for helping preparation of figures. We are grateful to associate editor A. Malehmir and the reviewers G. Bellefleur, P. Hatherly, C. Krawczyk, and one more anonymous reviewer whose comments and advice are greatly appreciated, and were crucial for improving the quality of the manuscript. Finally, we are grateful to Landmark graphics, a Halliburton company, for providing us with $3 \mathrm{D}$ processing and interpretation packages within the Landmark-Curtin educational and research grant. We also are grateful to Hampson \& Russell, a CGGVeritas company, and ION Geophysical Corporation for providing survey design and AVO software packages.

\section{REFERENCES}

Barnes, S. J., R. E. T. Hill, C. S. Perring, and S. E. Dowling, 2004, Lithogeochemical exploration for komatiite-associated Ni-sulfide deposits: Strategies and limitations: Mineralogy and Petrology, 82, 259-293, doi: 10.1007/s00710-004-0051-7.

Calvert, A. J., and Y. Li, 1999, Seismic reflection imaging over a massive sulfide deposit at the Matagami mining camp, Quebec: Geophysics, 64, 24-32, doi: 10.1190/1.1444521.

Cowden, A., and D. E. Roberts, 1990, Komatiite- hosted nickel sulfide deposits, Kambalda: Australasian Institute of Mining and Metallurgy Monograph, 14, no. 1, 576-582.

Dentith, M. C., K. F. Frankcombe, and A. Trench, 1994, Geophysical signatures of Western Australian mineral deposits: An overview: ASEG Special Publications, Extended Abstracts, 1, 29-84.

Greenhalgh, S. A., and I. M. Mason, 1997, Seismic imaging with application to mine layout and development, in A. G. Gibins, ed., Geophysics and geochemistry at the millenium: Proceedings of Exploration 97, GEOFX Publishers, 585-598.

Jones, S., 2007, Structural analysis of Beta-hunt, Kambalda: Consolidated Minerals unpublished internal report.

Lesher, C. M., 1989, Komatiite-associated nickel sulfide deposits: Reviews in Economic Geology, 4, 44-101.

Malehmir, A., and G. Bellefleur, 2009, 3D seismic reflection imaging of volcanic-hosted massive sulfide deposits: Insights from reprocessing Halfmile Lake data, New Brunswick, Canada: Geophysics, 74, no. 6, B209-B219, doi: 10.1190/1.3230495.

Milkereit, B., E. Adam, A. Barnes, C. Beaudry, R. Pineault, and A. CinqMars, 1991, An application of reflection seismology to mineral exploration in the Matagami area, Abitibi belt, Québec, in current research, Part C: Geological Survey of Canada, Paper 92-1C, 13-18.

Milkereit, B., E. K. Berrer, A. R. King, A. H. Watts, B. Roberts, E. Adam, D. W. Eaton, J. Wu, and M. Salisbury, 2000, Development of 3D seismic exploration technology for deep nickel-copper deposits - A case history from the Sudbury basin, Canada: Geophysics, 65, 1890-1899, doi: 10 $.1190 / 1.1444873$.

Milkereit, B., D. Eaton, J. Wu, G. Perron, M. Salisbury, E. Berrer, and G. Morrison, 1996, Seismic imaging of massive sulfide deposits, part II: Reflection seismic profiling: Economic Geology, 91, 829-834, doi: 10.2113/ gsecongeo.91.5.829.

Mutton, P., and B. Peters, The Waterloo and Amorac nickel deposits, Western Australia: A geophysical case history: ASEG Special Publications, Extended Abstract, 1-14.

Neumayr, P., J. L. Walshe, L. Horn, K. Petersen, C. Deyell, K. Moran, D. Howe, K. Connors, N. Stolz, R. Morrison, and S. G. Hagemann, 2004, Hydrothermal alteration footprints and gold: CRC Conference, 165-169.

Stolz, E. M., 2003, Direct detection of gold bearing structures at St. Ives, WA - DHEM versus DHMMR: Exploration Geophysics, $\mathbf{3 4}$ 131-136.

Stone, W. E., and N. J. Archibald, 2004, Structural controls on nickel sulfide ore shoots in Archaean Komatiite, Kambalda, WA: The volcanic trough controversy revisited: Journal of Structural Geology, 26, 1173-1194, doi: 10.1016/j.jsg.2003.11.014

Stone, W. E., M. Heydari, and Z. Seat, 2004, Nickel tenor variations between Archaean komatiite-associated nickel sulfide deposits, Kambalda ore field, Western Australia: The metamorphic modification model revisited: Mineralogy and Petrology, 82, 295-316, doi: 10.1007/s00710-004-00455 .

Stone, W. E., and E. E. Masterman, 1998, Kambalda nickel deposits: Monograph, 22, 347-356.

Urosevic, M., A. Kepic, E. Stolz, and C. Juhlin, 2007, Seismic exploration of mineral deposits in Yilgarn Craton, Western Australia: Proceedings of Exploration 07.

Urosevic, M., E. Stolz, and S. Massey, 2005, Seismic exploration of complex mineral deposits - Yilgarn Craton, Western Australia: 67th Annual International Conference and Exhibition, EAGE, Extended Abstracts, Z-99. 